\title{
Care Seeking Behaviour of Older Adults with Hip Fracture in India: A Qualitative Study
} \author{
Webster $^{5}$, Robyn Norton ${ }^{2,6}$ \\ ${ }^{1}$ The George Institute for Global Health, New Delhi, India \\ ${ }^{2}$ The George Institute for Global Health, Nuffield Department of Obstetrics\& Gynaecology, University of Oxford, UK \\ ${ }^{3}$ Institute of Global Health Innovation, Imperial College, London, UK \\ ${ }^{4}$ Indian Institute of Public Health Bhubaneshwar, Public Health Foundation of India \\ ${ }^{5}$ Nuffield Department of Population Health, University of Oxford, UK \\ ${ }^{6}$ The George Institute for Global Health, Sydney Medical School, University of Sydney, Sydney, Australia \\ *AT \& SR contributed equally to this work
}

Abha Tewari ${ }^{1}$, Santosh Rath ${ }^{2,3}$, Lalit Yadav ${ }^{1}$, Kirti Sundar Sahu $^{1}$, Desaraju Shyama Sundari ${ }^{1}$, Sanghamitra Pati $^{4}$, Srinivas Nallala $^{4}$, Premila

\begin{abstract}
Background: Hip fractures among older adults is a serious public health issue in India due to increase in ageing population. Availability and timely access to surgical care is essential for reduction of mortality and morbidity from hip fractures and thereby decreasing inequalities among older adults. The notion of access to care is multi-dimensional and the "three-delay" framework can be applied to understand the causes for delay between sustaining a hip fracture and receipt of appropriate care. The aim of this study is to determine the processes in decision-making, identify cause for delays in obtaining care, and the potential barriers and facilitators to seeking appropriate care in time.
\end{abstract}

Methods: A qualitative study was conducted (30 in-depth interviews) in seven healthcare facilities (4 public; 2 private and 1 alternative care center) in two administrative district of Odisha, India. The study was undertaken by George Institute for Global Health, India, in collaboration with Indian Institute of Public Health-Bhubaneswar from July 2014 to January 2015.Participants were aged 50 years or older with hip fracture including males and females. Data was categorized using NVIVO software and analyzed by thematic analysis.

Results: Majority of participants perceived hip fracture injury will heal on its own and does not require surgery. They were not aware of the consequences of such an injury, comorbid conditions and available healthcare facilities. Family/community members played a significant role in the choice of surgeon and in accessing health care facility. Participants who had an injury outside their home were taken immediately to the hospital whereas those who fell inside home get delayed in reaching hospital. The delay from time of injury till access of care varied from few hours to months. People with a hip fracture and their relatives had strong faith and belief in traditional health care system, i.e. Traditional bonesetters within their local community.

Conclusion: Our study findings emphasize on the need for quick decision- making to access nearest health facility with the provision of surgical care. We recommended further research studies to be conducted in varied settings to widen our knowledge in care pathways for the management of hip fractures in India.

Keywords: Hip-fractures; Care-seeking; Patient; Behaviour; Qualitative; India

\section{Background}

Worldwide, as the population ages, the incidence of hip fractures will increase as a common serious injury in older adults, with associated high mortality [1]. Globally, incidence of hip fractures is projected to increase to 3.1 million by 2030 and 6.26 million by 2050 and half of these are expected to occur in Asia [2-4]. According to studies from India, the crude incidence of hip fracture is 105 and 159 per 100,000 among men and women respectively and one year mortality is $42 \%$ $[5,6]$. Developed countries like the UK, have emphasize on integrated health and social care to improve the outcome among older people $[7,8]$. Fast track admission to a suitable treatment center, co-management by geriatrician, early hip fracture surgery within $48 \mathrm{~h}$ and early postoperative mobilization reduced perioperative complication and, quicker discharge from hospital $[4,9]$. The UK National Hip Fracture Data base (NHFD) and the National Institute of Clinical Excellence (NICE) provide evidence based practice guidelines for managing older people with hip fracture and this guidance is followed globally [9].

Studies suggests that older adults have 5-8 fold increased risk for all-cause mortality during the first 3 months after hip fracture and early surgery can reduce mortality $[1,10]$. Timely access to surgical care is therefore essential for reduction of mortality and morbidity associated with hip fracture injury $[11,12]$. However, access to safe, affordable surgical and anesthesia care in a developing country like India is a big challenge, where nine of ten people cannot access basic surgical care [11]. Recently published hip fracture audit conducted in Odisha indicates high numbers of conservative treatment and great delays in surgery [13]. Often, patients turn to traditional health practitioners, as they are easily accessible, trusted and cheap compared to modern medical care [14,15]. Studies have shown that about $70 \%$ of primary health care needs of the Indian population are met with traditional medicine and similar trends are observed in other parts of Asia such as China, Thailand and Indonesia [16]. Currently there

*Corresponding author: Santosh Rath, The George Institute for Global Health, University of Oxford, 34 Broad Street, Oxford, OX1 3BD, T: +44(0)1865 617 208 F: +44(0)1865 617202 M; +44(0)7849795808; Email: s.rath@imperial.ac.uk

Received January 13, 2017; Accepted February 20, 2017; Published February 28, 2017

Citation: Tewari A, Rath S, Yadav L, Sahu KS, Sundari DS, et al. (2017) Care Seeking Behaviour of Older Adults with Hip Fracture in India: A Qualitative Study. J Pat Care 3: 128. doi: 10.4172/2573-4598.1000128

Copyright: ( 2017 Tewari A, et al. This is an open-access article distributed unde the terms of the Creative Commons Attribution License, which permits unrestricted use, distribution, and reproduction in any medium, provided the original author and source are credited. 
Citation: Tewari A, Rath S, Yadav L, Sahu KS, Sundari DS, et al. (2017) Care Seeking Behaviour of Older Adults with Hip Fracture in India: A Qualitative Study. J Pat Care 3: 128. doi: 10.4172/2573-4598.1000128

Page 2 of 8

is a paucity of information on the pathways of care and outcomes of older individuals with hip fractures in India.

In low resource settings like India, availability and timely access to surgical care facility is crucial for hip fracture management. The "threedelay" model developed to assess delays in accessing timely obstetric care provides a framework to understand the causes for delay between sustaining a hip fracture and receipt of appropriate care $[17,18]$. The First Delay-associated with decision-making to seek care is influenced by financial and geographic restrictions, family hierarchy, cultural beliefs, poor education, a low awareness of available services or low confidence in those services. The Second Delay - in reaching care - occurs when hospitals with surgical capacity are scarce or far away inadequate transportation facility. Access to private vehicles, ambulance service and public transport is not uniform across the state. The Third Delay - the delay in receiving care occurs when attendance at a hospital does not guarantee treatment $[19,20]$. The purpose of this study is to explore the processes in decision-making following a hip fracture in an older person, identify cause for delays in obtaining care, and the potential barriers and facilitators to seeking appropriate care in time, i.e., first and second delay of the "three-delay" framework (Figure 1).

\section{Methods}

\section{Study design}

A qualitative study was conducted in Khordha and Cuttack administrative districts of Odisha, from July 2014 to January 2015.
Odisha is a state in India with 46 million populations, comprising 30 administrative districts with limited healthcare facilities. The public health care system in Odisha comprises of a district hospital (DH), sub-centres, and primary care centres in each of the administrative districts with lower level of surgical facilities, as well as three tertiary care teaching hospitals for the entire state. There are many private care facilities, mostly in urban areas. Hip fractures are mostly treated in private hospitals located in the urban areas and the poor can afford care only at government care centres, which are overcrowded and are at a great distance from their homes. The study was undertaken by the George Institute for Global Health, New Delhi, in collaboration with Indian Institute of Public Health-Bhubaneswar, Odisha.

Seven facilities were purposively selected to obtain a wider perspective on care seeking behaviour of older adults following hip fractures. These facilities represented public, private and alternative care centers; Four tertiary care hospitals (two public and two private), two public secondary care hospitals and one Traditional bonesetters. The details of selected health facilities has been described in our study protocol paper [20]. Adults aged 50 years or older of both sexes arriving at these health facilities with a history of fall or injury with pain in the hip region and X-ray confirmed hip fractures were included in the study. Patients with terminal malignancies were excluded. Clinicians or care providers from these health facilities helped to identify the patients. Care provider introduced the researcher to the patient and facilitated consent procedure. Both verbal and written informed consent was obtained from each respondent before taking the interview.

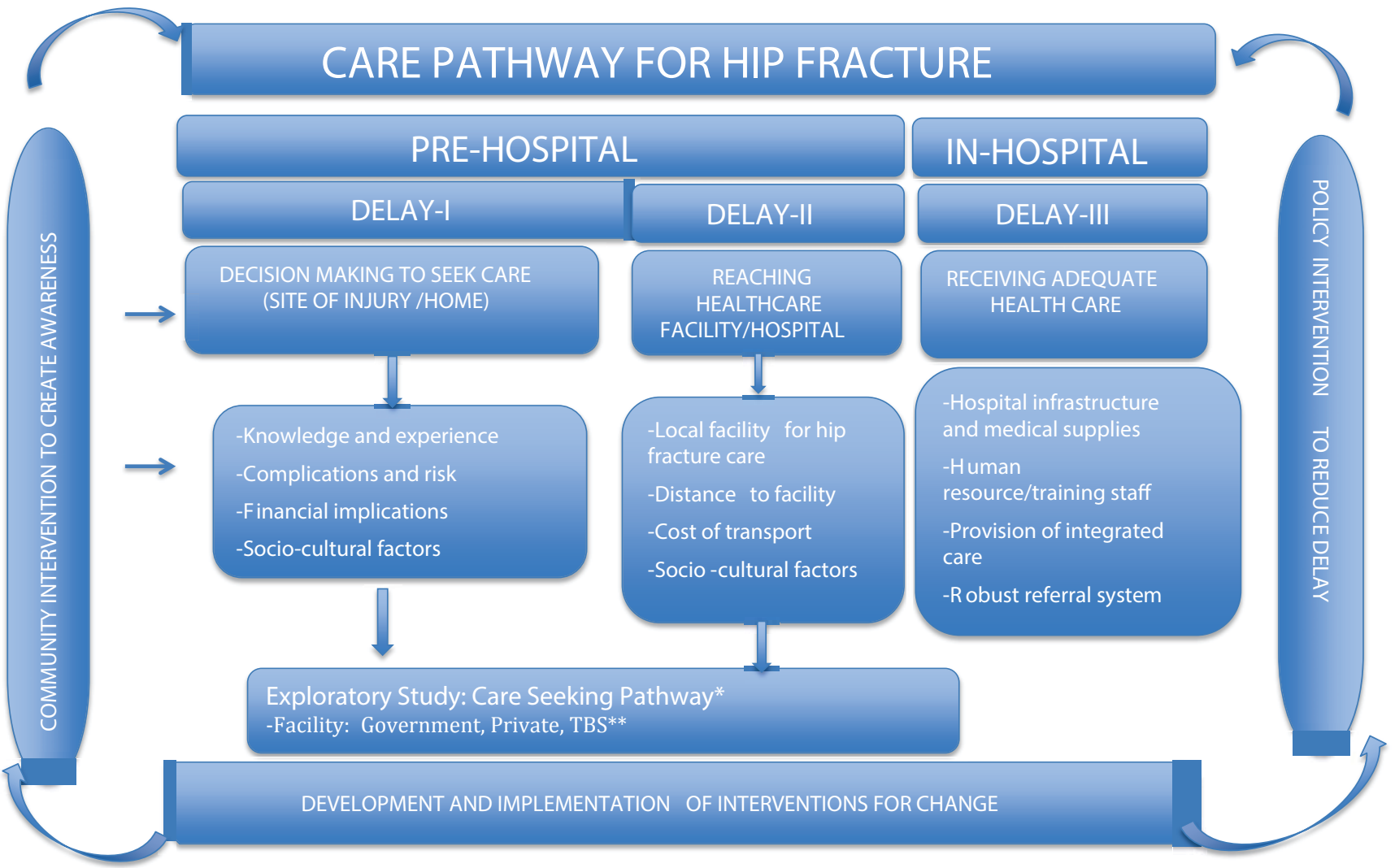

${ }^{*}$ Care seeking pathways of Older Adults with Hip Fractures in India: Exploratory study

** TBS- Traditional Bone-setting Centers

Figure 1: Proposed conceptual framework of care pathway for hip fracture management. 


\section{Data Collection}

Data was collected through 30 in-depth interviews with patients and carers' in the selected healthcare facilities. Following informed consent procedures, patients along with their carers were interviewed in the hospital settings. The patient with the hip fracture was the primary informant for the study and the carer was requested for additional information. All interviews were conducted by the two researchers experienced in qualitative research. Participants were asked to express themselves in their local language (Odia) in which they were most comfortable. All interviews were audio recorded and each interview took approximately 30-35 min. A list of questions in the interview guide was developed by the research team through discussion and consensus (Table 1). Refinement was based upon the initial interviews and discussion of the initial transcripts. The questions presented are core to the interviews; however, probes were introduced to clarify and enhance the quality of the interviews. The interview questions were translated from English to local language (Odia) and back translated from Odia to English by trained translators. To maintain the quality and accuracy of the translation these documents were checked by the research team members. The guide was pilot tested with participants not included in the study and revised accordingly (Table 1). Transcription of the data collected in this study was done by the research team members under the guidance of the principal researcher. The audio recorded interviews were first transcribed in Odia and then translated into English. Once the transcripts were translated to English, they were saved on a password-protected computer only accessible to the research team. Research team member conversant in both Odia and English cross-checked the transcripts for accuracy and language translation consistency [21].

Data were analyzed with the assistance of NVIVO 9 software program according to the framework analysis [22,23]. The transcripts of the interviews were reviewed and read (familiarization), during which a coding scheme was developed. The transcripts were coded by creating 'nodes' in the NVIVO program), with each node examined separately. In compliance with criteria for methodological rigor in qualitative research, two techniques were used for coding: primary open coding followed by thematic and selective coding. Two authors coded the first three interviews independently. After the first phase of primary coding, the group discussed the data and reached consensus on an initial coding tree. Coding categories were discussed and agreed to by all authors; divergent issues were discussed until the group reached agreement. In a second phase of thematic coding, links between different codes were analyzed and discussed to create a thematic coding structure $[24,25]$. Our study findings are congruent with three-delay framework, exploring causes of first and second delay events occurring prior to hospital arrival (pre-hospital).

\section{Results}

The findings are presented under distinct thematic categories that emerged from the interactions and whatever differences emerged in results by settings (public hospitals, private hospitals and traditional care centers) are mentioned separately. Quotes and conversational trends are presented to support our identified themes.

\section{Demographic profile of participants}

Of the 30 participants, 16 were women and 14 were men, aged between 50 and 81 years. Most of the female participants were illiterate or less educated. 'Illiterate' refers to those who were not able to read and write whereas less educated were those who could read or write or have elementary education (up to the level of primary education). Most of these were homemakers engaged mainly in household activities. Most males were educated and were either retired from work, or engaged in small business or jobs. Of the 30 participants, 19 were diagnosed with intra-capsular, nine with intertrochanteric fracture and the remaining two from traditional care center had inconclusive diagnosis on the type of hip fracture. The causes of fracture were a fall either inside or outside the home or from a road traffic injury. Various reasons were cited for falls: a slip in the bathroom or on their way to the toilet or while walking outside the home. Almost all the women had the injury within the household premises and road injury was the most common in the men (Table 2).

\section{Interview Questions}

$1 \quad$ Please tell us about the purpose of your hospital visit?

$2 \quad$ Please elaborate your personal experience /feelings during the time of injury /fall?

Could you please describe the events that have happened immediately after the injury?

Which of your family member/s supported you at that time? What was their initial reaction towards this event?

5 When did you decided to seek help from health care centre/hospital and how?

6 Are you aware of the existing health care centres/hospitals in your area? Give details

7 In your opinion what are other hospitals in your area which can provide similar kind of treatment/care? What are the reasons for choosing this hospital ?

8 How was your experience at the health care centre/hospital?

9 What treatment was given at the centre/hospital?

10 What was the second point/subsequent point of contact with health care facility? 10 Please give details.

11 Did you have any fracture before, If yes, could you tell us about it in detail?
Probes

Specific injury or event, site of injury, time, place etc

Symptoms related to discomfort, pain, bleeding, lost consciousness etc. Did you receive any help or support at that time? If yes, who supported you? What was their initial action?

Number of family members, decision maker in the family

First point of contact, who accompanied you, mode of transport, time took to reach the centre, any preliminary treatment

Facility, distance, cost, quality etc

Registration related, who attended you first, waiting period, any first aid given

Treatment, duration of stay, who paid for the treatment, referral to otherl higher Centre, reason for refer?

Treatment, duration of stay, who paid for the treatment?

Where was the fracture; When was the fracture; What did you do; Where did you seek treatment?

Did you go for physiotherapy/alternative treatment, was there any residual pain/ activity limitation post fracture/injury? Do you have any other health problem/concerns?

Table 1: Interview questions and probes

J Pat Care, an open access journal 


\begin{tabular}{|c|c|c|c|}
\hline & $\begin{array}{l}\text { Public hospital } \\
\text { patients } \\
(n=13)\end{array}$ & $\begin{array}{l}\text { Private hospital } \\
\text { patients }(n=13)\end{array}$ & $\begin{array}{c}\text { Traditional care } \\
\text { center patients } \\
\quad(n=4)\end{array}$ \\
\hline $\begin{array}{l}\text { Sex } \\
\text { Male } \\
\text { Female }\end{array}$ & $\begin{array}{l}5 \\
8\end{array}$ & $\begin{array}{l}7 \\
6\end{array}$ & $\begin{array}{l}2 \\
2\end{array}$ \\
\hline $\begin{array}{l}\text { Age (years) } \\
50-59 \\
60-69 \\
>70\end{array}$ & $\begin{array}{l}4 \\
1 \\
8\end{array}$ & $\begin{array}{l}3 \\
2 \\
8\end{array}$ & $\begin{array}{l}1 \\
1 \\
2\end{array}$ \\
\hline $\begin{array}{l}\text { Educational status } \\
\text { Illiterate } \\
\text { Literate(primary level) } \\
\text { Secondary } \\
\text { Graduate \& above }\end{array}$ & $\begin{array}{l}9 \\
1 \\
1 \\
2\end{array}$ & $\begin{array}{l}7 \\
3 \\
1 \\
2\end{array}$ & $\begin{array}{l}2 \\
1 \\
0 \\
1\end{array}$ \\
\hline $\begin{array}{l}\text { Occupation } \\
\text { Household work } \\
\text { Self-employed/Job } \\
\text { Retired }\end{array}$ & $\begin{array}{c}10 \\
2 \\
1\end{array}$ & $\begin{array}{l}6 \\
4 \\
3\end{array}$ & $\begin{array}{l}2 \\
2 \\
0\end{array}$ \\
\hline $\begin{array}{l}\text { Cause of the fracture } \\
\text { Fall } \\
\text { Injury on the road }\end{array}$ & $\begin{array}{l}9 \\
4\end{array}$ & $\begin{array}{c}12 \\
1\end{array}$ & $\begin{array}{l}3 \\
1\end{array}$ \\
\hline $\begin{array}{l}\text { Diagnosis } \\
\text { Intra-capsular fracture } \\
\text { Intertrochanteric fracture } \\
\text { Inconclusive diagnosed }\end{array}$ & $\begin{array}{l}7 \\
6 \\
0\end{array}$ & $\begin{array}{c}10 \\
3 \\
0\end{array}$ & $\begin{array}{l}2 \\
0 \\
2\end{array}$ \\
\hline
\end{tabular}

Table 2: Demographic profile, cause and fracture diagnosis.

\section{Perceptions of the injury and care}

The majority of the respondents from all three settings were unaware of the seriousness of the injury, the potential complications and the consequences of mortality and poor quality of life. None of the respondents knew that surgical treatment is essential for the management of hip fracture. They were also unaware that early surgery reduced complications and the risk of mortality. All the participants were unsure of which treatment facility to access in case of future event of similar fractures. A male respondent in a private hospital shared that, "I was going to take bath suddenly I felt dizzy and fell down. My son took me to doctor as we thought it (pain and other symptoms) will reduce by medicine, injections but it was not reduced". A female respondent from a public hospital said that, "for the last 10 days I was there [home] taking medicines and all... We had no idea. We thought the fracture would heal by its own within the body by taking medicines. As the pain increased then my son took me to hospital".

Respondents from public hospitals were unaware of the need for surgery. Those from traditional care facility believed that the fracture would heal on its own and did not require surgical intervention. Only few respondents from private facilities were aware about the need for surgery in the management of hip fracture. Majority of the respondents lacked knowledge on ways to prevent hip fracture in old age. A female respondent from a public hospital shared that "Yes...we had put plasters...those desi (locally made) plaster. They (care provider) said it is dislocated if it will be reduced with force then the joint will come to normal position and it will be alright." Most of the patients were independently managing their daily activities of living including household work before the injury. Recollecting their experience at the time of injury or fall, some patients were not able to stand due to severe pain. Few patients mentioned that they were confused, disoriented and were unable to remember the situation in which the injury occurred. A female respondent in a private hospital shared, "All are saying that I fell down but I have no idea what had happened. There was pain and tingling sensation throughout hip joint". Many of the patients from public hospitals felt that poor vision and weakness lead to the fall and fracture. A few patients from private hospitals felt that the cause of the injury could be associated with existing medical conditions like high blood pressure.

\section{Processes of decision making and support}

Most of the respondents expressed that family members (son, husband, daughter and son-in-law) are the ultimate decision-makers to seek treatment. A member's role is defined by their status as the breadwinner in the family. It was also observed that other family member had to be consulted so that they could contribute money for treatment One of the female respondents in a public hospital shared, "I am not an earning member and do not do anything. I am dependent on my children for money. After falling in the bathroom outside of my room, I screamed loudly; they (family members) took me inside my room but decided not to consult the doctor immediately". Many respondents from private hospitals emphasized the significant role and influence of family, friends and other community members in the choice of surgeon and facility for care. Previous hospitalization experience of a community member or those working in a hospital were major source of information various health facilities and treating professionals. Similarly half of the respondents from traditional care center had previous experience of such care. It was observed that older people tend to visit doctors with an established reputation or those recommended by other older people in the community

A male respondent commented, "I was known to this hospital before. My own son had a fracture and the bone got separated into 4 parts. I brought him here and he was cured. That is the reason why I came here". Findings from the study revealed that the majority of participants received support from family and friends immediately after the injury. Patients who sustained the injury at odd hours outside their home had to wait for nearly two hours for relatives to arrive before receiving any help. It was also noted that patients who sustained the injury outside their home were taken immediately to hospital by passers-by, whereas, those who had their injury at home were delayed in reaching hospital primarily due to the family decision making process. Thus, the role of the family was reported as both promoting and hindering in the care seeking process. In fewer cases, it was observed that there was a difference of opinion between the patient and the care-giver. For example, fewer patients specified that they had not completely recovered after their first injury but care- givers replied that they had recovered completely and made them to walk.

\section{Barriers for obtaining care and treatment}

Awareness of medical conditions, health facilities and ambulance services: Among respondents, knowledge and awareness about other medical conditions emerged as barriers to obtain timely care and treatment. Nearly half of the patients admitted in public hospitals were unaware about their health conditions and few had not been to a hospital since their childhood. Some of the patients admitted in private hospital were unaware about existing co-morbidities and were diagnosed after admission to the hospital. A female respondent from a private hospital said that, "After coming to this hospital, I came to know that I have high blood pressure (Hypertension)" A male respondent from a private hospital said, "After admission into the hospital, the doctor checked and gave the operation date for tomorrow but it got delayed due to diagnosis of high sugar (Diabetes)". Lack of awareness of existing healthcare facilities is a barrier to decision making. The majority of the respondents lacked knowledge of the existing health care facilities in their locality and those aware were uncertain if hip fracture treatment was available at the health facility. A few of the respondents from public hospitals shared that they opted to seek treatment in tertiary care 
hospital due to dissatisfaction with the local facility. Non-availability of the doctor in the local facility was cited as a common reason to seek treatment in tertiary care hospital. "No, actually we do not know any government hospital, we have heard about only AIIMS (hospital name), No we don't know about Cuttack medical college (hospital name)" Male respondent, private hospital.

Another male respondent from a private hospital commented: "Government (thinking for some time...) only small dispensary is there in rural area but doctor's availability is a big issue. Private Doctors are there and after retirement they have opened clinic and providing services." Respondents from private healthcare facilities shared that public facilities were not equipped to provide proper treatment for hip fractures. A male respondent from a public hospital mentioned that, "Hmm... there are hospitals but they do not have the facilities." "No... there is no proper treatment there, they are not responsible and as such there is no facility available there". Most of the participants were aware of the " 108 " ambulance service provided by the government; though very few of the respondent used this ambulance service to reach the health care facility. Many respondents from both public and private health care settings mentioned that they dialled for " 108 " but did not wait for the ambulance, as they feared the patient may die from delay. Most used private transport like auto-rickshaw, motorcycle and rental car to reach the hospital, depending on their financial condition. "We came here in a tempo (Auto) and we did not wait for 108(Ambulance service) because she is an old woman and we feared that she may die. So, we called a tempo because there was no time to wait" (Female, Public hospital)

Faith and belief in traditional care system: Many respondents believed that Traditional bonesetters provided effective treatment at affordable cost. Various reasons were cited to express their belief in the traditional care system. A common reason was ease of access compared to hospitals. Many perceived that treatments by Traditional bonesetters were safer, and did not require surgery or implants. A male respondent from a traditional care setting shared, "within the hospital, surgery involves invasion of body parts by incision and stitching, believe it will lead to complications and need to stay in ICU, isolated from family, thus not prefer medical hospital for such type of problem" Faith in Traditional bonesetters was reinforced by community experience of alternative care. The general belief was that Traditional bonesetters are efficient in their treatment as they use age old methods, and treat only bones and fractures. A male respondent from a traditional bone center shared, "Here people over 100 years of age getting cured. During my time in the center, 10-12 persons returned home after getting well...Do not take your patient to any medical hospital they will do surgery and there is no after care. Here everything is under personal care". Some respondents from public hospitals reported that they used both traditional and modern care.

Fewer began treatment with traditional care and then shifted to a hospital; while a few reached the traditional care center after surgery. Some respondents from private hospitals shared that they had been to a doctor immediately after injury and then moved to Traditional bonesetters. All respondents from the traditional centers shared that they had previous experience with the system either through a family or community member or personally. A male respondent from a public hospital mentioned, "traditional care center (bone-setters) is accessed by, many famous personalities like doctors, army men, etc. Herbal medicines are prescribed which have a strong healing effect on fractured bones. Even older people get cured and many of our villagers are coming here for treatment.

Referral, time lag and financial constraints: Most of the respondents received medication for pain relief, at the first point of contact, usually a local hospital and X-ray was used to establish a diagnosis.. The majority of patients were referred to a tertiary care hospital from the local or district hospital due to lack of equipment or non- availability of doctors. A few were however brought directly to a tertiary care center after a fall. Several patterns of referral were observed, i.e., private-to-private, public to private, private to public and hospital to traditional care and vice a versa. Most of the referrals were from public to public and self-referral from public to private care. The number of referrals ranged from zero to five. In most cases, the respondents adhered to a recommended referral but a few choose to ignore the advice and go to traditional bonesetters. A respondent from a private hospital said, "I stayed for eight days at a hospital near my house. The doctor prescribed some medicines and applied traction...but there was no progress for almost eight days than I spoke to a known doctor at this hospital [different] and came here in ambulance. After reaching here, we waited for more than two weeks for the operation (surgery). The investigations informed that I am having high blood sugar and reduce sodium levels. Finally my surgery was done" There was a variation in the time period between date of injury and seeking treatment at a hospital following hip fractures among the patients.

The time lag between the injury and arrival at the treating hospital varied from hours to months. Some of the patients reached hospital within a day or two of the injury, whereas a few were delayed by 1-2 months. A female respondent from private hospital, "After my fall, my son took me to Bhapur (primary care hospital)... and then to Khorda [District hospital] where they took photo (X-ray) and advised me to keep the leg straight and prescribed some tablets. We returned home... and the pain increased...so they took me to capital hospital [regional hospital]... then they referred me to Cuttack hospital [tertiary referral hospital] but we returned home... and finally came to this hospital and they put this traction." Out of pocket, expenditure was a major concern for the patient and carer. They expressed their anxiety over the expenses for treatment accessories, medication and implant. The uncertainty over the waiting period for surgery and length of stay in hospital was a worry for most. Daily living costs for the accompanying care and associated cost due to long waiting periods for surgery and uncertain length of stay were causes of financial concern. The majority of the respondents however were unable to provide precise information on the expenditure incurred since the injury till the time of the interview. One of the patient in the public hospital mentioned that, "since he had no money to buy medicines, he was taking only those medicines supplied free of cost." Another male respondent, in a private hospital shared, "He is not being operated since we have no money for the treatment." Many of the respondents both in public and private hospitals had some type of public or private health insurance. Some had a below poverty line [BPL] card which provided them treatment at a public or a private health facility, free of charge or at a concessional rate. Many respondents many were unable to utilize the benefits of the BPL card for reasons like card expiry or non-acceptance of the scheme in some hospitals. A male respondent from a private hospital said, "We are not able to get any benefits because of this below poverty line (BPL) card-expiry or may be other reasons. We are poor and had to spend from our pocket."

\section{Suggestions from the patients/carers}

Respondents were asked to provide suggestions based on their experiences to improve health facilities for hip fracture management The majority of the respondents suggested upgrading government facilities in their region to treat hip fractures. They also emphasized that these facilities should be easily accessible, affordable and efficient in providing care. Respondents mostly from private hospitals also 
Citation: Tewari A, Rath S, Yadav L, Sahu KS, Sundari DS, et al. (2017) Care Seeking Behaviour of Older Adults with Hip Fracture in India: A Qualitative Study. J Pat Care 3: 128. doi: 10.4172/2573-4598.1000128

Page 6 of 8

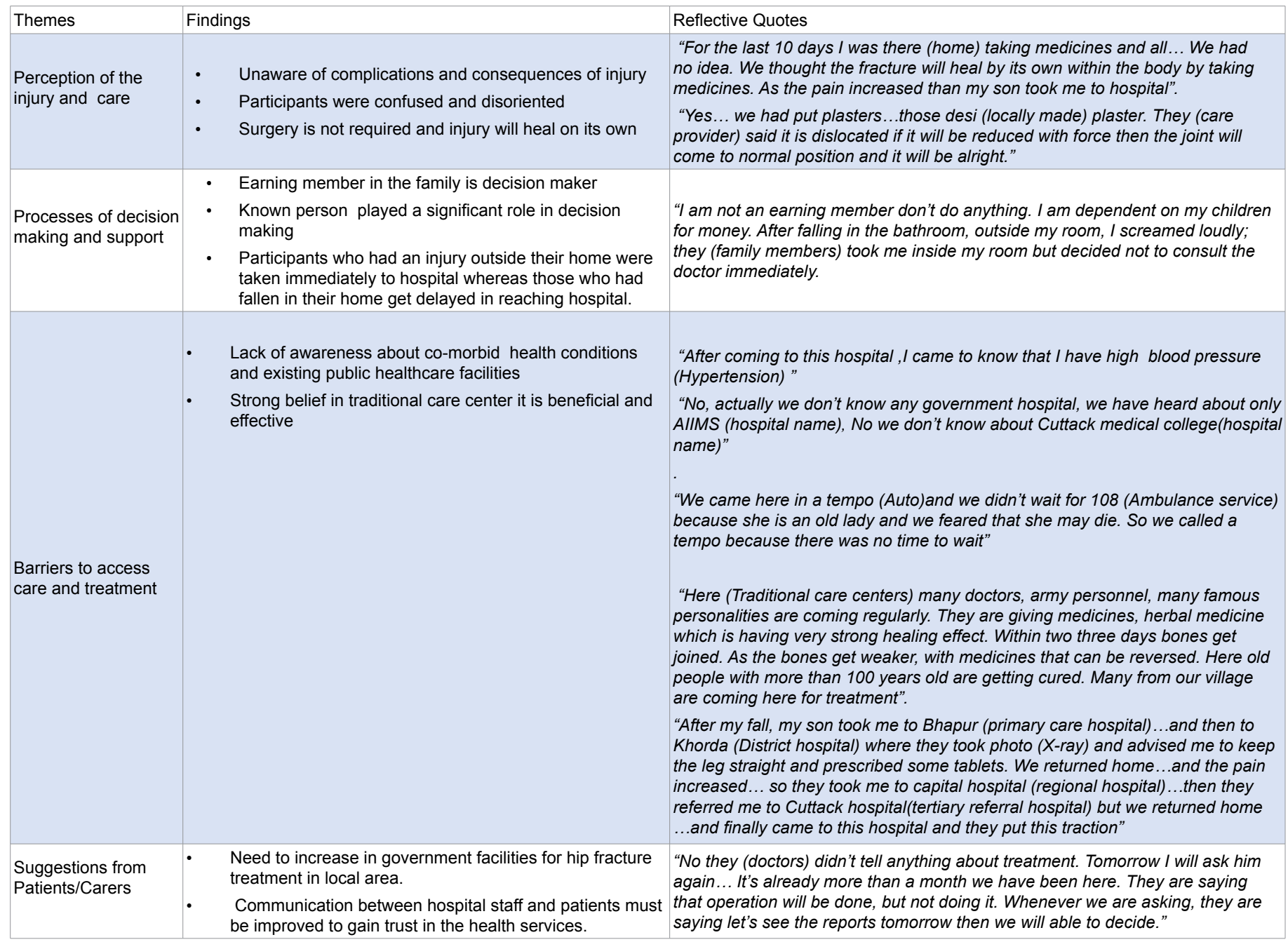

Table 3: List of Themes and Findings.

suggested the need to understanding the recommended treatment and that decision-making for early surgery. They also suggested the need for better communication between hospital staff and patients to gain trust in the health services. "No they [doctors] didn't tell anything about treatment. Tomorrow I will ask him again...It's already more than a month we have been here. They are saying that operation will be done, but not doing it. Whenever we are asking, they are saying let's see the reports tomorrow then we will able to decide." Male respondent from Private hospital (Table 3).

\section{Discussion}

The study provides insight into numerous factors influencing careseeking behaviour of older people with hip fractures in Odisha, India. Many of these relate to the general lack of awareness of health, poor knowledge of care facilities and community opinions on care pathways [26]. The decision-making is solely reliant on the breadwinner of the family. Factors like out-of-pocket expenditure, low confidence in public health facilities, and faith in alternative care influence decision making. Selection of care facility is influenced by past experiences of family and friends, and not through triage or referral within the organized health system. Lack of family or community perception on the serious nature of a hip fracture and the need for early surgery for an older adult is a barrier to appropriate and timely decisions. Surmounting these decision-making barriers at home consumes time and contributes to the first delay in care seeking pathway. Our findings suggest that patients sustaining injury at home were more susceptible to delays in seeking care than those injured outside the home. In few instances when the injury occurred outside the home in urban settings, the patients were triaged to a hospital with public assistance and avoided the delays from family decision-making processes. Gender and age inequities in some communities may also contribute to the decisions for neglect and care at home. Co-existing morbidities, extreme ill health and poor quality of life prior to the fracture may influence the decision not to seek further care [27]. There is strong faith and belief in alternative care in the community under study. Easy access, non-invasive method of treatment, and low cost are reasons cited in favor of Traditional bonesetters. Past experiences of successful fracture treatment in younger age groups in the community is a major contributor to Traditional bonesetters' popularity. As relatively few hip fractures are treated by traditional bonesetters, death and complication from immobilizing hip fractures in older adults may be infrequently experienced in the traditional care setting $[28,29]$. There is no published report on outcomes of hip fractures treated by Traditional bonesetters for comparison with surgical care.

Knowledge and perception barriers, health systems constraints, social and financial barriers impede care seeking decisions [30]. There 
is ample evidence that early surgery for hip fracture in older adults reduces mortality, and therefore, speed in the decision making to seek surgical care is crucial. The lack of proper triage leads to multiple hospital transfers and contributes to delay, as patient's waste time in local hospitals without facilities for surgery. For those seeking private care, finding/locating a reliable facility with adequate expertise for hip fracture management consumes time. Fee-paying patients often undertake cost comparison of various hospitals and doctors' fees and this adds to further delay. For those with health insurance, the choice of hospital was predetermined by the insurer and facilitated quicker decisions.

The findings of this study indicate, lack of knowledge on the appropriate treatment of hip fractures and awareness of existing comorbidities in older adults. Lack of awareness on caring needs, the hospital facilities, and reliance on friends and family for guidance for health care is reflected across the study group. These cause delays in decision-making and are barriers to best practice for the management of older adults with hip fractures. The absence of triage and referral process burdens the family to investigate and select care facilities and imposes significant logistic and cost [31]. Strengthening the health systems to enable proper diagnosis, triage and referral to suitable facilities can prevent delay in hip fracture care and other conditions requiring emergency surgical care [32]. Health systems interventions along with educational and awareness-raising strategies can significantly reduce the delays in decision-making. Increasing awareness of health conditions and regular screening for common non-communicable diseases will reduce un-necessary delays for treating undiagnosed co-morbidities. Appropriate health insurance coverage and effective mechanism of disbursement has the potential to reduce the financial barrier for seeking care. Wider coverage of health insurance schemes could provide incentives for the development of care facilities, processes for triage and referral system [33].

Timely arrival to a hospital will enable best practices for the management of older adults with hip fracture and be an exemplar for surgical service systems strengthening. The major limitation of this study is the exclusion of older people with hip fractures not seeking care in a hospital or a traditional care centre. Patients attending primary care hospitals lacking facility for hip fracture surgery are referred and it is likely that some do not travel to tertiary care due to financial or logistic issues. The recruitment of patients limited to urban tertiary care hospital is a significant limitation and the study findings cannot be generalized for the entire population. Although the study indicated faith in Traditional bonesetter but the inclusion of only four respondents recommend further exploration of the factors influencing choice of traditional care for hip fractures. A strength of the current work is that it is one of the few studies to provide a detailed knowledge of the care seeking behavior from a patient's perspective. Qualitative studies are limited in their generalizability; however, compared with quantitative studies, they can provide informative insights. Our sample was drawn from only one state, i.e., Odisha, which limits generalizability to other geographical regions, In addition, including the perceptions of the doctors and health care provider in a study would add valuable information.

\section{Conclusion}

This study investigated care-seeking behavior for older adults with hip fracture, allowed in-depth analysis of the decision-making processes in the family, and the barriers and facilitators in the care-seeking pathway. The events and factors identified in decision-making process for hip fractures are likely to be similar for other health conditions requiring urgent hospitalization and surgery. Further studies are needed using this study methodology to widen our knowledge of the care seeking pathways for health conditions requiring surgery in India.

\section{Declarations}

\section{Ethics approval and consent to participate}

The study protocol including processes for obtaining and managing informed consent from participants has been evaluated and approved by the ethics committee of the Center for Disease Control (CCDC, New Delhi) (IEC/04/2014) and Government of Odisha (224/ SHRMU/31.07.2014).The informed consent from the participants were obtained to participate in the study and to publish the findings.

\section{Competing interests' statement}

The authors declare that they have no competing interests.

\section{Authors Contribution}

.AT and SR prepared the first draft of the manuscript that has been discussed thereafter by all the authors. SR and RN conceptualize and design the research plan for the study. AT with support from KSS and DSS conducted the interviews with the study participants. LY supported for data analysis and interpretation. SP and SN provided critical inputs on the manuscript. AT with supervision and guidance from SR and RN provided the ultimate version of the manuscript. All authors read and approved the final manuscript.

\section{Availability of Data and Materials Statement}

The datasets during and/or analysed during the current study is available from the corresponding author upon reasonable request.

\section{Acknowledgement}

We would like to thank all participating hospitals, all participants and team members involved in the study for giving their valuable time. We acknowledge the Department of Health, Government of Odisha, India for ethics approval and for facilitating the study.

\section{Funding}

This work was supported by internal funds provided through the Nuffield Department of Population Health, University of Oxford.

\section{References}

1. Haentjens P, Magaziner J, Colon-Emeric CS, Vanderschueren D, Milisen $K$ Velkeniers B, et al. (2010) Meta-analysis: Excess mortality after hip fracture among older women and men. Ann Intern Med 152: 380-390.

2. Cooper C, Campion G, Melton LJ III (1992) Hip fractures in the elderly: A worldwide projection. Osteoporos Int 2: 285-289.

3. Johnell O, Kanis JA (2004) An estimate of the worldwide prevalence, mortality and disability associated with hip fracture. Osteoporos Int 15: 897-902.

4. http://www.hqip.org.uk/assets/NCAPOP-Library/NCAPOP-2012-13/HipFracture-Database-Audit-Report-pub-2012

5. Dhanwal DK, Dennison EM, Harvey NC, Cooper C (2011) Epidemiology of hip fracture: Worldwide geographic variation. Indian J Orthop 45: 15-22.

6. Khadgawat R, Brar KS, Gahlo M, Yadav CS, Malhotra R, et al. (2010) High prevalence of vitamin $D$ deficiency in Asian-Indian patients with fragility hip fracture: A pilot study. J Assoc Physicians India 58: 539-542.

7. Ashton L (2001) Promoting the health and social care of older people: Gaining a perspective from outside the UK. J R Soc Promot Health 121: 152-158.

8. Roe B, Beech R, Harris M, Beech B, Russell W, et al. (2011) Improving quality 
Citation: Tewari A, Rath S, Yadav L, Sahu KS, Sundari DS, et al. (2017) Care Seeking Behaviour of Older Adults with Hip Fracture in India: A Qualitative Study. J Pat Care 3: 128. doi: 10.4172/2573-4598.1000128

Page 8 of 8

of life for older people in the community: Findings from local partnerships for older people project innovation and evaluation. Prim Health Care Res Dev 12: 200-213.

9. http://www.nice.org.uk/guidance/cg124/resources/guidance-hip-fracture

10. Neuburger J, Currie C, Wakeman R, Tsang C, Plant F, et al. (2015) The impact of a national clinician-led audit initiative on care and mortality after hip fracture in England. An external evaluation using time trends in non-audit data. Med Care 15: 686-691.

11. Meara JG, Leather AJM, Hagander L, Alkire BC, Alonso N, et al. (2015) Global surgery 2030: evidence and solutions for achieving health, welfare, and economic development. Lancet 386: 569-624.

12. British Orthopaedic Association (2007) The care of patients with fragility fracture ("Blue Book").

13. Dash SK, Panigrahi R, Palo N, Priyadarshi A, Biswal M (2015) Fragility hip fractures in elderly patients in Bhubaneswar, India (2012-2014): A prospective multicenter study of 1031 elderly patients. Geriatric Orthopaedic Surgery and Rehabilitation 6: 11-15

14. Thanni LO (2000) Factors influencing patronage of traditional bone setters West Afr J Med 19: 220-224.

15. Ogunlusi DO, Ikem IC, Oginni LM (2007) Why patients patronize traditional bonesetters. The Internet Journal of Orthopedic Surgery 4: 1-7.

16. Fang HC, Wu YW, Shang TY (1996) The integration of modern and traditional Chinese medicine in the treatment of fractures. Clin Orthop Relat Res 323: 4-11.

17. Thaddeus S, Maine D (1994) Too far to walk: Maternal mortality in context. Soc Sci Med 38: 1091-1100.

18. Tahzib F, Daniel SO (1986) Traditional medicine and the modern curriculum Lancet 2: 203-204.

19. Grimes CE, Bowman KG, Dodgion CM, Lavy CB (2011) Systematic review of barriers to surgical care in low-income and middle-income countries. World J Surg 35: 941-950.

20. Tewari A, Sahu KS, Yadav L, Pati S, Nallala S, et al. (2015) Care seeking pathways of older adults with hip fracture in India: Exploratory study protocol. Int J Equity Health 14: 130

21. Regmi K, Naidoo J, Pilkington $P$ (2010) Understanding the processes of translation and transliteration in qualitative research. Int J Qual Methods 9: 16-26.

22. Srivastava A, Thomson SB (2009) Framework analysis: A qualitative methodology for applied policy research. JOAAG 4

23. http://www.qsrinternational.com/product

24. Silverman D (2015) Qualitative research: SAGE Publications Ltd.

25. Matthew B, Miles A, Huberman M, Saldana J (2013) Qualitative data analysis A methods sourcebook.

26. Balarajan Y, Selvaraj S, Subramanian SV (2011) Health care and equity in India. Lancet 377: 505-515.

27. Channon AA, Andrade MV, Noronha K, Leone T, Dilip TR (2012) Inpatient care of the elderly in Brazil and India: Assessing social inequalities. Soc Sci Med 75: 2394-2402.

28. OlaOlorum DA, Oladiran IO, Adentran A (2001) Complications of fracture treatment of traditional bone setters in southwest Nigeria. Fam Pract 18:635-637.

29. Panda AK, Rout S (2011) Puttur kattu (bandage)-a traditional bone setting practice in south India. J Ayurveda Integr Med 2: 174-178.

30. Rath S \& Dey AB (2017). Management of Older People with Hip Fractures in China and India: A Systems Approach to Bridge Evidence-Practice Gap. In: Textbook of Ortho-Geriatrics. Eds. Falaschi P and Marsh D: Springer, Switzerland. ISBN 978-3-319-43249-6 (eBook)

31. Moran CG,Wenn RT, Sikand MS, Taylor AM (2005) Early mortality after hip fracture: Is delay before surgery important? J Bone Joint Surg Am 87: 483-489.

32. Fahy SA,Wong F, Kunasingam K, Neen D, Dockery F, et al. (2014) A review of hip fracture mortality-Why and how does such a large proportion of these elderly patients die? Surg Sci 5: 227-232.

33. Shaikh M, Woodward M, Rahimi K, Patel A, Rath S, et al. (2015) Use of major surgery in south India: A retrospective audit of hospital claim data from a large, community health insurance programme. Surgery $157: 865-873$. 